\title{
DETERMINISTIC APPROACH TO PREDICTING THE FATIGUE CRACK GROWTH IN THE 2024-T3 ALUMINUM ALLOY UNDER VARIABLE AMPLITUDE LOADING
}

\author{
Dorota Kocańda, Janusz Torzewski \\ Military University of Technology \\ Warsaw, Poland
}

\begin{abstract}
The paper presents the attempt to predict fatigue crack growth rate in a component subjected to variable amplitude loading containing overload-underload cycles. For this goal in a deterministic approach the modified Willenborg retardation model was applied. To provide experimental data the research into fatigue crack growth for 2024-T3 aluminum alloy sheet CCT specimens under LHL type block program loading with multiple overload-underload cycles was developed. The microfractographic analysis of fatigue fractures with the use of the transmission electron microscope (TEM) made it possible to trace the effect of block program loading on the crack growth rate. The knowledge of the affection of a particular overloadunderload cycle or a block of these cycles on crack rate on the basis of microfractographic analysis was utilized for assessing the equivalent loading for the LHL block program. The diagrams that presented the crack growth rate both on the surface and inside the aluminum alloy sheet was performed. The crack growth rate inside the sheet was estimated on the basis of the striation spacing analysis.
\end{abstract}

Keywords: aluminum alloy, fatigue crack growth rate, microfractographic analysis, Willenborg retardation model

\section{INTRODUCTION}

As far as structural materials are concerned, the process of the fatigue crack growth is different under constant- and variable-amplitude loading. The operational spectrum of a structure is a typical variable amplitude spectrum. Physical phenomena which are characteristic for variable amplitude loading are the reason for variable behavior of structural materials. In the case of variable-amplitude loading, the fatigue crack growth is influenced not only by the initial crack length and load at a given moment but also by the load history. It is referred to as load interaction. The effect of single and multiple overload (OL) or underload (UL) cycles, which occur cyclically or randomly in a spectrum, on the increase of the formation of fatigue cracks in aircraft aluminum alloys has been extensively discussed in literature [Ref. 1- 6, among others]. There exist numerous physical mechanisms that accompany the formation of fatigue cracks under variable-amplitude loading. The most frequently mentioned mechanisms are plasticity induced crack closure [Ref. 7] and crack growth retardation associated with the plastic zone induced by an tensile-overload cycle. Compressive underload cycle, on the other hand, leads to the crack tip sharpening and the crack growth increase. The change in the crack front contour prior to and after the overload cycle results in the crack tip blunting [see Ref. 6]. It ought to be emphasized that the distribution of residual stresses in the plastic zone and ahead of the crack front [Ref. 8], the thickness of a particular component as well as the mechanical properties of the material are determining factors that contribute to irregular fatigue crack growth. The crack growth rate is influenced by the first cycle in a block of load cycles as well as the ordering of OL/UL (overload/underload) or UL/OL 
(underload/overload) within the cycle sequences. The research conducted on the aluminum alloy of Russian D16 (the equivalent of the American alloy 2024-T3 shows [Ref. 9] that cyclic OL/UL cycles interspersed with constant-amplitude base load cycles delay the crack growth in components, while UL/OL cycles increase the crack growth rate.

A considerable interest is to evaluate the capacity of the models for fatigue crack growth prediction. For this goal a research program into fatigue crack growth behaviour has been developed for thin 2024 sheets after two different heat treatments T3 and T2 under variable amplitude sequences typical to helicopter utilisation to support analytical and numerical modelling of crack growth in lower wing skin [10]. It was stated that 2024-T2 specimens exhibited slightly longer crack propagation lives with respect to 2024-T3 Alclad specimens. Accuracy and the reliability of the prediction models commonly used by FASTRAN, NASGRO, CORPUS and AFGROW have been tested to evaluate the plots of crack length versus number of cycles as well as the distribution of the ratio of the number of cycles measured in the experimental test over the calculated ones, for a given crack growth intervals. The results of comparisons showed big discrepancies between these plots. The retardation and acceleration effects due to imposed overloads have been clearly marked on the experimental plots. The trends in crack growth behaviour have been illustrated only by three predicted plots. The worst results were derived by AFGROW. Crack growth analysis for 7075-T6 aluminium alloy under service loading with the help of identical numerical programs as mentioned in [10] was the subject of the work [11]. A wide review of fatigue crack growth behaviour for the metallic materials, among them also for aluminium alloys, under variable amplitude both simple and complex load sequences as well as the presentation of fatigue crack growth prediction models contains the monograph [12].

The influence of the shape of the loading spectrum of a structure component on the fatigue crack growth rate is analyzed by means of electron microscopy. The fracture surface of a particular component is examined with the use of scanning electron microscope (SEM) and transmission electron microscope (TEM). However, more accurate information concerning the effect of particular cycle sequences in a spectrum on the crack rate characteristic for a given component can be obtained from the microfractographic analysis performed with the use of the TEM due to its depth of focus. It is particularly crucial in the case of extensive fracture surfaces of components, which can be observed in the 2024-T3 aluminum alloy. Extensive fracture surfaces are created due to the presence of numerous intermetallic phases in the alloy structure. The local crack growth rate is assessed on the basis of the image of fatigue striations on the fracture surface. The fatigue striation system are created by a specific sequence of load cycles. The local crack growth rate can be estimated by means of striation spacing measurement. The details of the microfractographic analysis concerning the 2024-T3 aluminum alloy and its correlation with the fatigue crack growth rate under single and multiple overloads can be found in Ref. [13-17].

The calculative model for predicting the fatigue crack growth in the 2024-T3 alloy under block program loading was developed on the basis of experimental data concerning the crack growth rate of model components as well as the findings of the microfractographic analysis. The abovementioned issue is the subject matter of this paper.

\section{RESEARCH MATERIAL AND METHODOLOGY}

Experiments concerning the fatigue crack growth rate were conducted on the 2024-T3 aluminum alloy, which is used for lower skin aircraft wing structure. The alloy was produced in Pechiney-Rhenalu plant (France). The material that was used were $3 \mathrm{~mm}$ thick sheet plated with pure aluminum on both sides (Alclad aluminum alloy sheets). The film of the plate had the thickness of $0.12 \mathrm{~mm}$. According to the manufacturer's certificate, the chemical composition of the 2024 alloy contains the following alloy elements: $\mathrm{Cu}(4.23 \%), \mathrm{Mg}(1.37 \%), \mathrm{Mn}(0.50 \%), \mathrm{Fe}$ $(0.18 \%), \mathrm{Zn}(0.16 \%), \mathrm{Si}(0.09 \%)$. The ranges of the mechanical properties of the alloy are as 
follows: tensile strength $\mathrm{S}_{\mathrm{u}}=441 \div 450 \mathrm{MPa}$; yield strength $\mathrm{S}_{02}=297 \div 309 \mathrm{MPa}$; percent elongation $\mathrm{A}=22 \div 25 \%$. The T3 designation indicates the aluminum alloy's solution heat treating $\left(495^{\circ} \mathrm{C}, 50\right.$ hours), cold rolling and natural aging at $195{ }^{\circ} \mathrm{C}$. The specimens of $400 \mathrm{~mm}$ length and $100 \mathrm{~mm}$ width were cut out from the sheet. Subsequently, a central hole, which was $5 \mathrm{~mm}$ in diameter, was cut inside each specimen. The hole was notched and had an initial pre-crack, the total length of which was $7.5 \mathrm{~mm}$ on both sides of it (Fig 1.). Counting the length from tip to tip of pre-cracking, the initial crack was equaled to $2 \mathrm{a}=15 \mathrm{~mm}$. The hole served as a crack initiator. Two series of specimens were made. LT-type specimens were cut out parallel while TL-type specimens were cut out perpendicularly to the sheet rolling direction.

Fatigue tests on the specimens were carried out at room temperature under load control variable stress amplitude in accordance with the diagram given in Fig 2.
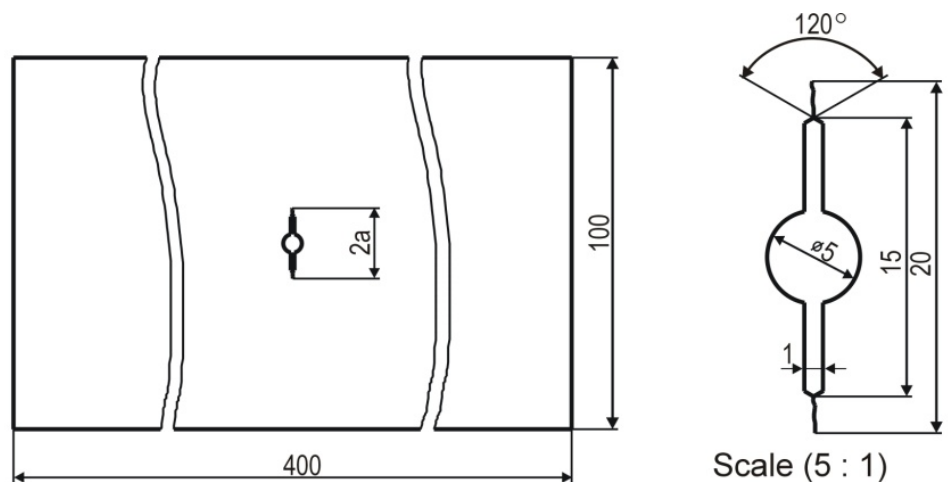

Fig 1. Fatigue test specimen geometry

The loading spectrum, which is usually abbreviated to LHL-100 (gradually increasing and decreasing) was developed in the Institute of Aviation, Warsaw, for the tests on the growth of fatigue cracks in aircraft wings. The spectrum represents 100 aircraft flights. It consists of thirteen blocks of cycles. The total number of cycles in block program is 2400 . The frequency of fatigue test was $5 \mathrm{~Hz}$ at the initial load level $(72 \mathrm{MPa})$ and $2 \mathrm{~Hz}$ at other levels. The crack growth on the specimen surface was recorded optically without interrupting the fatigue test. Electron-optical examination of crack surfaces of sheets was conducted with the use of SEM and TEM microscopes. The effect of particular loading blocks on the crack growth rate was deduced from the images of fatigue striation system and the striation spacing measure.

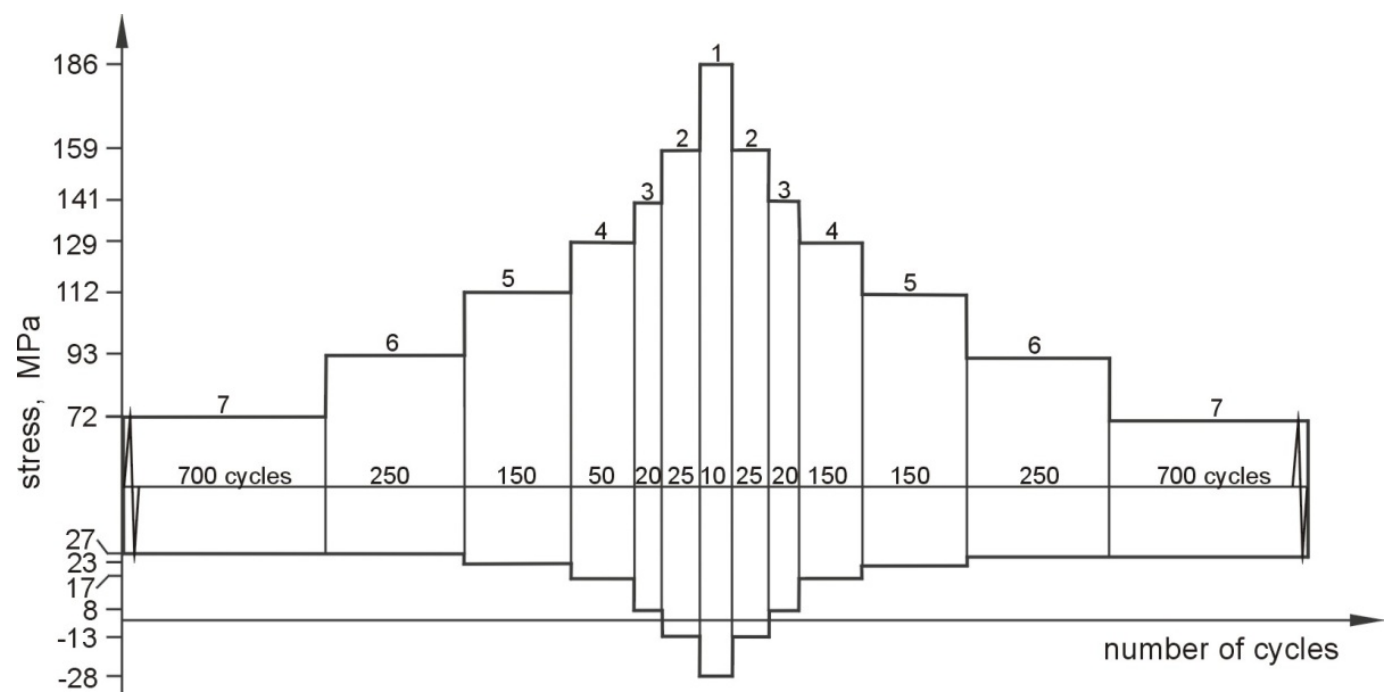

Fig 2. The LHL-100 block program loading 


\section{FATIGUE CRACK GROWTH RATE IN 2024-T3 ALLOY UNDER BLOCK PROGRAM LOADING}

The effect of multiple overload/underload (OL/UL) cycles existing in the LHL-100 spectrum on the crack growth rate and the formation of fatigue striations on the surface of the 2024-T3 aluminum alloy sheet was examined on the basis of the results of fatigue tests and the microfractographic analysis. Exemplary courses of crack propagation rates in LT-type and TLtype specimens depending on the crack length are illustrated in Fig 3. For any comparison the plots of growth rates in LT I TL specimens recorded under CA zero-to-tension loading $(\mathrm{R}=0.1)$ were also inserted in the diagrams, respectively.
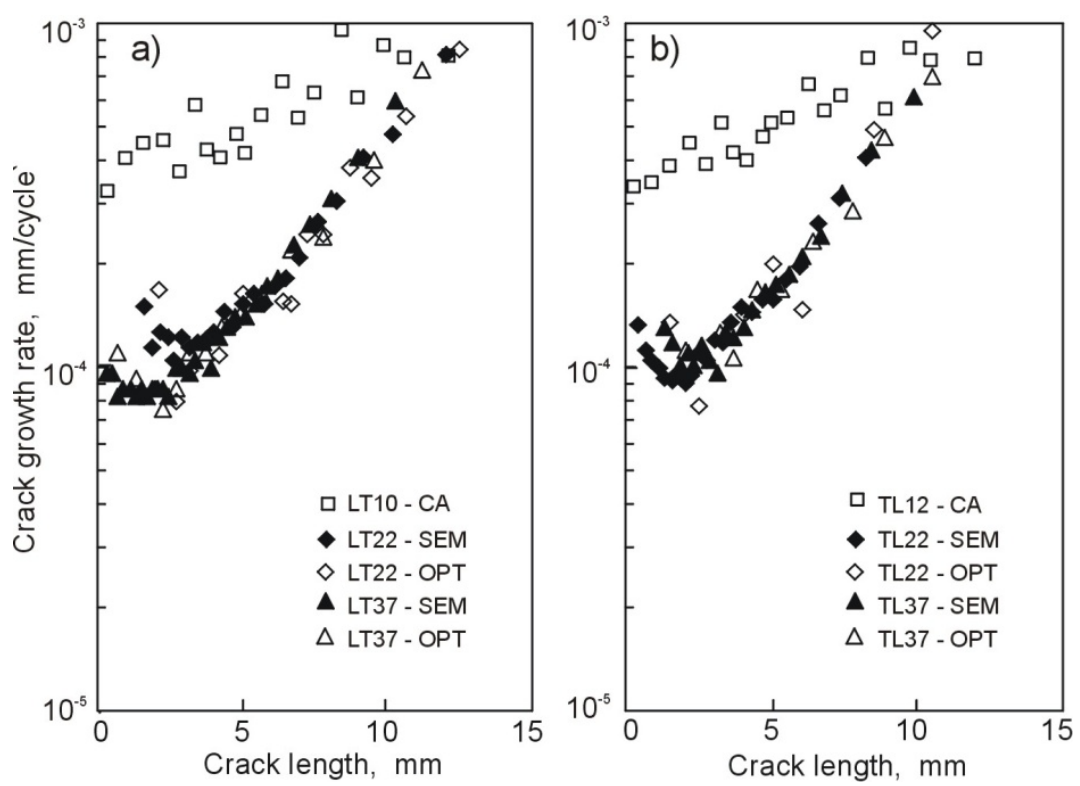

Fig 3. Crack growth rate diagrams for LHL-100 block program and CA loading against crack length drawn for LT samples (a) and TL samples (b) of 2024-T3 alloy

As could be expected the VA loading has significantly reduced the crack growth rates in both specimens in comparison to the rates observed under CA loading. In the above diagrams open (white) symbols mark the surface crack length of specimens measured by optical method (OPT), whereas blackened symbols indicate the length of the crack advances inside the sheet (crack depth), which was assessed on the basis of spacing measurements between the fatigue striations visible on the fracture surface of the specimen with the use of SEM microscope. As can be seen in Fig. 3 in $3 \mathrm{~mm}$ thick 2024-T3 alloy sheet either surface crack (OPT) or crack depth (SEM) advance at similar rates. The LT specimens (Fig. 3a) exhibit greater scatter of the rates during fatigue lives than the TL specimens (Fig. 3b). It means the dependence on the cutting out direction of specimen to the sheet rolling direction when the specimens are subjected to variable amplitude loading. However, the crack growth rate decreases or shows invariability within the range of 10-15 loading sequences, which is seemed in Fig $3 \mathrm{a}$ and $3 \mathrm{~b}$. This kind of crack behavior indicate a strong influence of plastic zone produced by the highest load level in the spectrum on the crack rate. This influence is particularly visible for small crack range. Compressive stresses in the plastic zones cause a temporary crack closure. The presence of a narrow striations or merely traces of these ones as well as the fault of striations on the fracture surface that was observed with the help of TEM microscope, are the confirmation of a crack arrest or its growth at very low rate [Ref. 13-17].

Exemplary image of the shape and the size of the zone of plastically deformed material recorded by a profile measurement gauge on the LT specimen's surface made of 2024-T3 alloy provides works $[18,16]$. The plastic zone associates with the crack growing from the notch root 
under LHL-100 block program. The values suited the particular contour lines indicate the depth of material plastic deformation, and on the other side, it can be understood as the intensity of plastic deformation which occur ahead of crack tip as well as in the wake of the crack. Black circle areas which are located along and ahead of a growing crack adherent to cyclic plastic zones. In these zones yielding occurs either in tension or in compression cyclic stress and their size is four times smaller than the size of monotonic plastic zones.

The courses of local growth rates attributed to the particular stress level either in descending or in ascending part of LHL-100 program against crack length are shown in Fig. 4 for three distances from the notch root (pre-cracking). On double horizontal axis are marked the intervals of the crack length in millimetres, counting from the pre-cracking, whereas on the lower axis the crack length increment in micrometers is calculated from the striations spacing. As it is seen first level block with ten spike overloads-underloads strongly reduces the growth rates in all blocks. It confirms also the importance of first cycle in each block in producing highest crack increment. The successive cycles in the block change in a small range only the striations spacing. It means the growth rate was almost constant within the block. It should be emphasized that the correlation between the striation systems and the appropriate load blocks was possible for establishing only for the stress levels labelled from 1 to 3 in descending part and respectively for 3-1 levels in the ascending part of the LHL-100 program. When following the blocks labelled from 4 to 7 (2300 cycles together) the crack growth rate drops to minimum value of $10^{-6} \mathrm{~mm} /$ cycle or even below it and the crack is arrested. This effect is more pronounced for first applied load program. In result the crack was arrested for 2300 cycles. It suits almost $95.5 \%$ of the LHL-100 program duration. On the contrary the propagation period covered only 100 cycles which states $4.5 \%$ of the time of load program affectation. The behaviour of crack growth rate under LHL block program is strongly depended on the plastic induced crack closure as well as the changes of stress distribution at the crack tip.

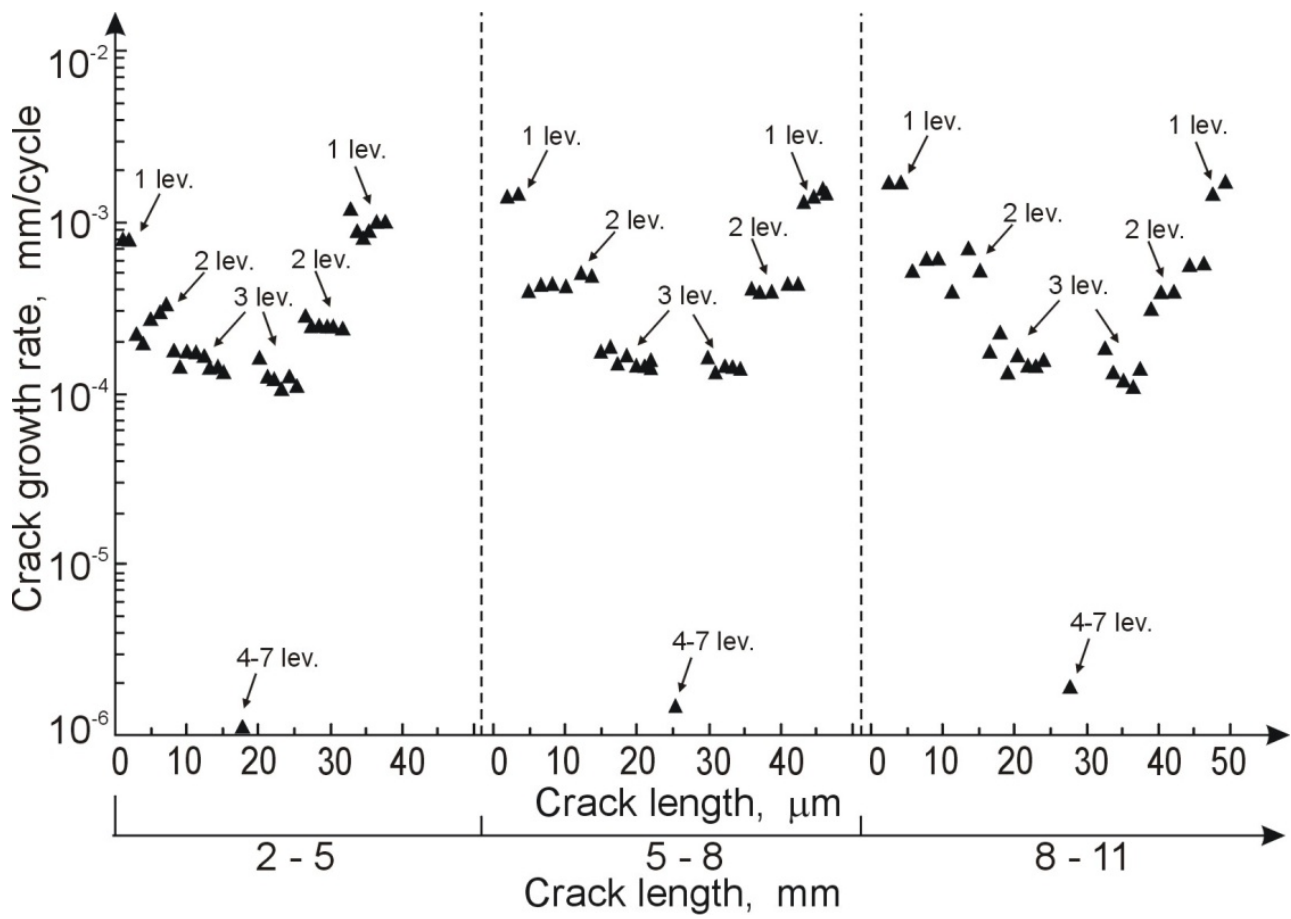

Fig 4. The crack growth rate in the 2024-T3 aluminum alloy for three different crack length ranges in the decreasing and increasing part of two successive loading spectra reconstructed on the basis of the images of striation units taken by using TEM 
The microfractographic analysis proved that short loading cycle sequences (as regards the number of cycles) and successive loading blocks which occur at relatively short intervals reduce the possibility of complete reconstruction of the loading spectrum on the basis of the microfractographic analysis in damaged components.

\section{PREDICTING FATIGUE CRACK GROWTH UNDER BLOCK LOADING}

To qualify quantitatively the influence of the operational loading spectrum on the fatigue crack growth rate of a structure component, the spectrum is replaced with a predetermined loading program. It is required that the model and the real object are physically identical as regards the time and point of crack initiation, the crack propagation period and the fatigue durability of the component. The analytic form of the predetermined loading spectrum is a statistic function of stress distribution, the parameters of which depend on time, or an equivalent block spectrum with the number of cycles in particular blocks corresponding to the number of occurrence of the particular value of stress $\left(\sigma_{i}\right)$ in the spectrum. In literature [19,21], it is suggested that the block program loading can be replaced with a load program of constant amplitude of equivalent stress $\left(\Delta \sigma_{\mathrm{eq}}\right)$. It concerns both symmetric and asymmetric fatigue cycles.

On the basis of the experimental results of crack growth rate study curried out for the specimens which were cut out from 2024-T3 aluminium alloy sheet and loaded under LHL-100 block program as well as the results of microfractographic analysis of the specimen fracture surfaces the authors suggested a replacement loading model for predicting the fatigue crack growth in components subjected to similar loading. The microfractographic analysis showed that in the case of mentioned loading conditions the cracks advanced only under three highest load levels (32-1-2-3). Other stress blocks had no or little influence on the accumulation of fatigue failures in specimens. The factor that contributed to that was the plastic zone which was created ahead of a propagating crack tip by the block of cycles with the highest load level in the spectrum (the first load level). High compressive stress induced in the plastic zone was delayed the crack propagation. Basing on the above-mentioned observations, a replacement spectrum for the LHL100 loading program was adopted (as shown in the diagram in Fig. 5).

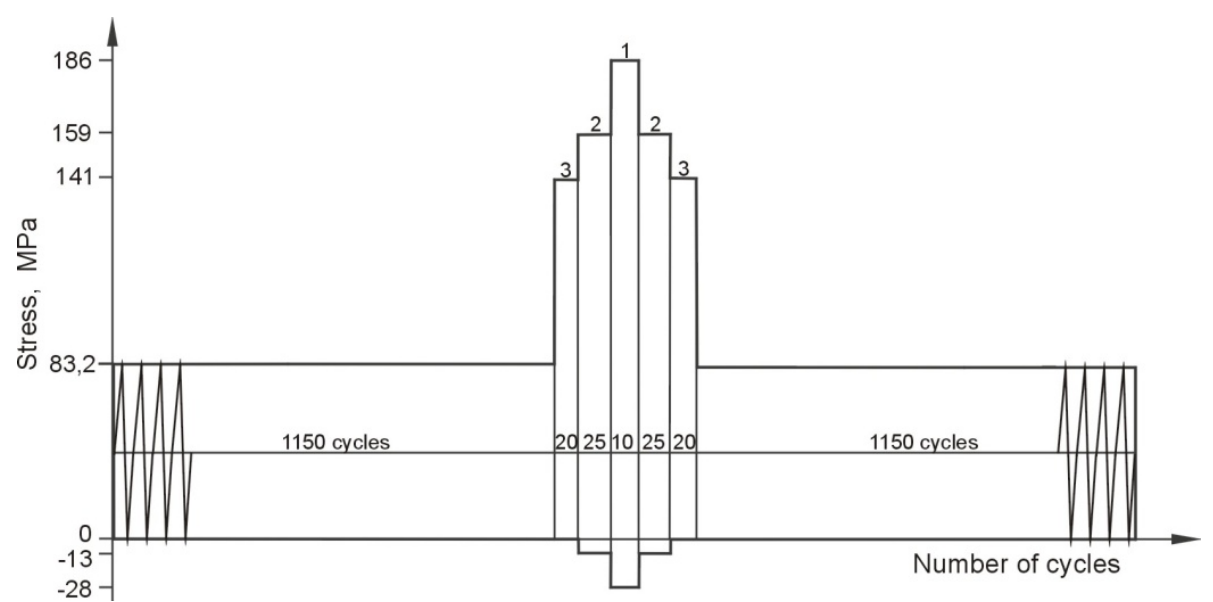

Fig. 5. Replacement loading program adopted in the model for calculations (explained above)

The replacement loading program consists of the basic constant-amplitude zero-to-tension load of an equivalent stress range $\Delta \sigma_{\mathrm{eq}}(\mathrm{CA})$ and five block cycles of 3-2-1-2-3 load levels that intersperse the baseline program. The CA load counts 1150 cycles that correspond to the sum of the cycles gathered in the blocks of 7-6-5-4 load levels. Equivalent stress range $\Delta \sigma_{\mathrm{eq}}$ for CA program was estimated on the basis of the relation (1) presented in Ref. [19]: 


$$
\Delta \sigma_{\mathrm{eq}}=\left[\sum_{\mathrm{j}=1}^{\mathrm{q}} \mathrm{n}_{\mathrm{j}}\left(\Delta \sigma_{\mathrm{j}}\right)^{\mathrm{m}} / \mathrm{N}_{\mathrm{B}}\right]^{1 / \mathrm{m}} \text { where: } N_{B}=\sum_{j=1}^{q} n_{j}
$$

where $n_{\mathrm{j}}$ is the number of cycles corresponding to the $\mathrm{j}$-th loading block; $q$ is the number of loading blocks; $N_{\mathrm{B}}$ is the number of cycles in CA loading program. The value of the fatigue crack growth exponent $m$ for aluminum alloys most frequently is 3.58 .

Klesnil [19] and then Walker [20] suggested that the effect of the stress ratio $R$ on the crack growth rate should be taken into account while calculating stress changes in the block spectrum. If one substitutes equation (2) into equation (1), then the blocks of 7-6-5-4 load levels initially having asymmetric cycles $(R \neq-1)$ are replaced by a constant-amplitude cyclic zero-to-tension load program $(R=0)$ according to the equation:

$$
\Delta \sigma_{j}=\sigma_{\max , j} \cdot\left(1-R_{j}\right)^{\gamma} j=1 \ldots q, R_{j} \geq 0
$$

where $\sigma_{\mathrm{max}, \mathrm{j}}$ and $R_{\mathrm{j}}$ are the maximum stress and the stress ratio for $\mathrm{j}$-th stress block, respectively. The value of the stress modification factor $\gamma$ is 0.68 for aluminum alloys under variable-amplitude loading with the stress ratio $R \geq 0$. For plastic materials and blocks of cycles with $R<0$ the value of $\gamma$ is within the rage of $0 \div 0.2$ [20]. Conclusively, the equivalent stress range $\Delta \sigma_{\text {eq }}$ for the CA load program presented in Fig. 3 is determined from the following equation:

$$
\Delta \sigma_{e q}=\left[\sum_{j=1}^{q} n_{j} \cdot\left[\sigma_{\max , j} \cdot(1-R)^{\gamma}\right]^{m} / N_{B}\right]^{1 / m}
$$

For the exponent $m=3.58$ then the equivalent stress range $\Delta \sigma_{\mathrm{eq}}=83.2 \mathrm{MPa}$.

Let's assume that crack growth rate under LHL-100 block program loading with $R \neq-1$ as well as under replacement loading program is expressed by the Paris formula. While determining the crack length increase under 1-2-3-2-1 stress levels, each cycle is considered individually. Therefore, the crack length increase $\Delta a_{\mathrm{bl}}$ under total number of cycles $N_{\mathrm{B}}$ can be determined from the following relation:

$$
\Delta a_{b l}=\sum_{j=1}^{N_{B}} a_{j}=\sum_{j=1}^{N_{B}} C \cdot\left(\Delta K_{j}\right)^{m}=\sum_{j=1}^{N_{B}} C \cdot\left(M_{k} \cdot \Delta \sigma_{j} \cdot \sqrt{\pi \cdot a_{j}}\right)^{m}
$$

where $C$ is the crack growth constant; $M_{k}$ is the magnification factor; $\Delta K_{j}=K_{\max , j}-K_{\min , j}$ is the stress intensity factor range for the $j$-th cycle; $a_{j}$ is the crack length measured at the point where the cycle with stress range $\Delta \sigma_{j}$ is applied. The average crack propagation rate per cycle can be represented by the following equation [see Ref. 20]:

$$
\left(\frac{d a}{d N}\right)_{\text {sred }}=\frac{\Delta a_{b l}}{N_{B}}=C \cdot\left(\left[\sum_{j=1}^{N_{B}}\left(\Delta K_{j}\right)^{w} / N_{B}\right]^{1 / w}\right)^{w}
$$

Basically, the exponents $m$ and $w$ in the Paris formulae (4) and (5) can have different values. According to the above assumptions, the value of the average crack propagation rate $(d a / d N)$ is equal to the rate determined from the Paris formula for the equivalent stress range $\Delta \sigma_{\text {eq. }}$. The crack in a component may propagate if it is an open crack, namely if the range of equivalent stress intensity factor $\Delta K_{e q}$ exceeds the value $\Delta K_{o p}$ connected with crack opening stress. As a result, the 
crack propagates under lower stress level, which corresponds to the effective stress intensity factor range $\Delta K_{\text {eq,eff }}$ as presented in the relation (6):

$$
C \cdot\left(\left[\sum_{j=1}^{N_{B}}\left(\Delta K_{j}\right)^{w} / N_{B}\right]^{1 / w}\right)^{w}=C \cdot\left(\Delta K_{e q, e f f}\right)^{m}=C \cdot\left[\Delta K_{e q}-\Delta K_{o p}\right]^{m}=C \cdot\left[(1-R) \cdot\left(K_{\text {max }, e q}-K_{\text {max }, o p}\right)\right]^{m}
$$

For the 2024-T3 aluminum alloy $K_{\text {max,op }}$ is within the range of $1 \div 3 \mathrm{MPa} \mathrm{m}^{1 / 2}$.

In the materials the fatigue crack growth rate depends considerably on the stress ratio $R$ and the thickness of a given component. The effect of the stress ratio $R$ on the fatigue crack growth rate is connected with the phenomenon of crack closure. Clack closure occurs during an underloading (a compressing part of fatigue cycle) if the minimum applied stress $\sigma_{\min }$ is lower than the crack closure stress $\sigma_{c l}$. This phenomenon occurs mainly during fatigue cycles with low negative $R$ values. A closed crack does not propagate. The phenomenon of crack closure does not occur under loads with high $R$ values. In this case, the crack is always open and can propagate. The difference of the values of the crack closure stress and the crack opening stress is the order of $15 \%$. In order to eliminate the effect of the stress ratio $R$ on the crack growth rate, then experimentally determined crack growth rate curves $d a / d N=f\left(\Delta K_{\text {eff }}\right)$ for cyclic loads with $R \neq 0$ are transformed to crack growth curves $d a / d N=f\left(\Delta \bar{K}_{\text {eq,eff }}\right)$ related to equivalent CA zero-to-tension load ( $R=$ $0)$. We obtain:

$$
\Delta \bar{K}_{R=0}=K_{\max , R \neq 0} \cdot(1-R)^{\gamma}=\Delta K_{R \neq 0} \cdot(1-R)^{\gamma-1}=\frac{\Delta K_{R \neq 0}}{(1-R)^{1-\gamma}}
$$

The above equation makes it possible to collapse the crack growth rate data onto a single trend line, which is illustrated in Fig. 6. In Fig. 6, open (white) symbols indicate experimentally determined crack growth rates under constant-amplitude (CA) load with the stress ratio $R=0.1$ (transformed in accordance with the relation (7)) as well as crack growth rates under constantamplitude cyclic zero-to-tension loading equivalent to the LHL-100 program. Whereas filled-inblack symbols indicate experimentally determined crack growth rates under variable-amplitude (VA) LHL-100 program. Thanks to the transformation of curves it can be proved that all differences in crack growth rates $(\Delta V)$ result only from the effect of overload blocks of cycles that occur in the LHL-100 spectrum on the crack retardation. Therefore:

$$
\begin{aligned}
& \Delta V=V_{C A}-V_{V A}=\left(\frac{d a}{d N}\right)_{C A}-\left(\frac{d a}{d N}\right)_{L H L-100}=C_{C A}\left(\Delta \bar{K}_{e q, e f f}\right)^{m}-C_{C A} \cdot\left(1-C_{P}\right) \cdot\left(\Delta \bar{K}_{e q, e f f}\right)^{m}= \\
& =C_{C A} \cdot C_{p} \cdot\left(\Delta \bar{K}_{\text {eq,eff }}\right)^{m}
\end{aligned}
$$

where $V_{C A}$ is the crack growth rate under the CA zero-to-tension loading spectrum; $V_{V A}$ is the experimentally determined crack growth rate under the LHL-100 block program loading; $C_{C A}$ and $m$ are material constants, $K_{\text {eq,eff }}$ is the effective stress intensity factor related to the equivalent stress range $\Delta \sigma_{e q}$.

After the transformation, equation (8) takes the form (9): 


$$
\frac{d a}{d N}=\Delta V=C_{C A} \cdot C_{p} \cdot\left(\Delta \bar{K}_{e q, e f f}\right)^{m}=C_{C A} \cdot C_{p} \cdot\left[(1-R) \cdot\left(\bar{K}_{\text {max }, e q}-K_{\text {max }, o p}\right)\right]^{m}
$$

The relation explicitly points to the influence of two phenomena on the rate of the crack growth in components. The phenomena are crack opening or crack closing depending on the type of fatigue cycles and the crack growth retardation due to the creation of the plastic zone ahead of the crack tip by overload cycles in the spectrum. Compressive stresses are induced in the plastic zone. $K_{\max , o p}$ factor is interrelated with the crack opening stress.

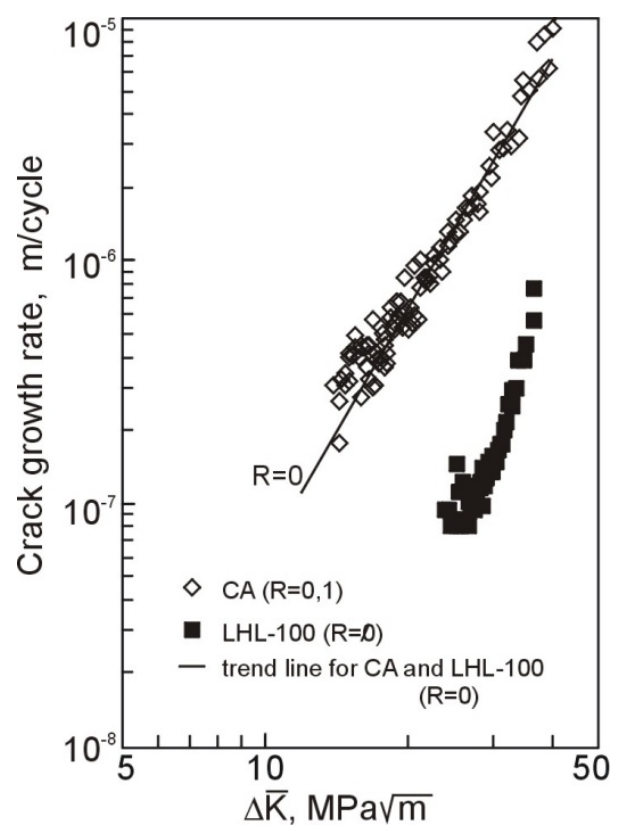

Fig 6. The experimentally observed crack growth rate under CA loading and the LHL-100 block program as well as the trend line for the crack growth rate under loading with $R=0$ as a function of the parameter $\Delta \bar{K}$; see text for explanation

The crack growth retardation is characterized by the retardation factor $C p$ defined by the equation:

$$
C_{p}=\left(\frac{r_{p i}}{a_{O L}+r_{p, O L}-a_{i}}\right)^{n}
$$

where $r_{p, O L}$ and $r_{p i}$ are the overload plastic zone size and the size of the plastic zone created by the current cycle in the loading program with the stress range $\Delta \sigma_{i}$, respectively. Whereas $a_{O L}$ is the crack length measured at the point where an overload cycle with stress range $\Delta \sigma_{o l}$ is applied; $a_{i}$ is the crack length corresponding to the $i$-th current cycle of the stress range $\Delta \sigma_{i}, n$ is the strain hardening exponent. Crack lengths $a_{i}$ and $a_{O L}$ were calculated in accordance with the Willenborg retardation model.

The Willenborg model is a modification of the Wheeler retardation model. In the Willenborg model, there was introduced a reduced stress $\sigma_{\text {red }}$ which is needed so that the crack of the length $a_{i}$ together with its current plastic zone $r_{p i}$ corresponding to the $i$-th load cycle could get through the plastic zone $r_{p, O L}$ which was created by the tensile-overload cycle. The model does not account for the effect of the operation of overload/underload cycles (OL/UL). Numerous literature reports [Ref. 3,4,12, among others] as well as our own observations indicate that an underload cycle 
occurring after an overload cycle reduces the crack growth delay period. UL-type cycles accelerate the crack growth rate. For that reason, a modification to the equation (10) must be made. Under compressive stresses in an underload half-cycle, both plastic zones, namely the current plastic zone with radius $r_{p}$ and the overload plastic zone with radius $r_{p, o l}$ are reduced by the size of the plastic zone with radius $r_{c p}$. In accordance with Ref. [22], the plastic zone radius $r_{c p}$ is determined by the equation:

$$
r_{c p}=\frac{1}{D \cdot \pi}\left(\frac{\Delta K_{U L}}{2 \cdot R_{02}}\right)^{2}=\frac{1}{D \cdot \pi}\left(\frac{K^{*}-K_{\min , U L}}{2 \cdot R_{02}}\right)^{2}
$$

where $D=2$ (plane stress state) or 6 (plane strain state), $K^{*}=\min \left(K_{\min }^{C A}, K_{t h}\right) ; K_{\min }^{C A}$ is the minimum stress intensity factor in a base CA cycle; $K_{t h}$ is the threshold stress intensity factor; $K_{\min , U L}$ is the minimum $K$ associated with the underload (UL); $R_{0,2}$ is the yield stress.

The crack growth retardation effect continues as long as the following relation is true:

$$
a_{i}+\left(r_{p i}-r_{c p i}\right)<a_{o l}+\left(r_{p, O L}-r_{c p, U L}\right)
$$

Strictly speaking, the crack growth is delayed as long as the crack of the length of $a_{i}$, including the current monotonic plastic zone with the radius $r_{p i}$ reduced by the size $r_{c p i}$ of the plastic zone, does not go beyond the overload plastic zone with the radius $r_{p, O L}$ associated with $a_{O L}$ overload crack length and reduced by the size $r_{c p, U L}$ of the plastic zone. Therefore, the retardation factor $C p$ is given by the equation:

$$
C_{p}=\left(\frac{r_{p i}-r_{c p i}}{a_{O L}+\left(r_{p, O L}-r_{c p, U L}\right)-a_{i}}\right)^{n}
$$

Strain hardening exponent $n$ that appears in equation (13) can be determined from experimental data or from the relation mentioned in Ref. [22]:

$$
n=O L R+M_{k}^{2}=\frac{\sigma_{\max , O L}}{\sigma_{\max }^{C A}}+M_{k}^{2}
$$

where $\sigma_{\max , O L}$ is the maximum of applied stress in an overload cycle and $\sigma_{\max }^{C A}$ is the maximum of applied stress in a constant-amplitude base load cycle.

The stress redistribution occurs ahead of the crack tip as a result of the interaction of an elastic material in the vicinity of the crack with compressive stresses acted in monotonic plastic zone. Assuming that the reduced stresses $\sigma_{\text {red }}$ operate in the plastic zone, the condition for the retardation of crack growth in the Willenborg model is as follows:

$$
a_{O L}+\left(r_{p o}-r_{c p, U L}\right)=a_{i}+\frac{1}{D \cdot \pi}\left(\frac{K_{r e d}}{R_{0,2}}\right)^{2}=a_{i}+\frac{1}{D \cdot \pi}\left(\frac{\sigma_{r e d} \cdot \sqrt{\pi \cdot a_{i}} \cdot M_{k}}{R_{0,2}}\right)^{2}
$$

The stress required for getting through the plastic zone is determined by the equation: 


$$
\sigma_{r e d}=\frac{\sqrt{2} \cdot R_{0,2}}{M_{k}} \cdot \sqrt{\frac{a_{o l}+\left(r_{O L}-r_{c p, U L}\right)-a_{i}}{a_{i}}}
$$

where $M_{\mathrm{k}}$ is the magnification factor.

In the model, it is assumed that [21] the value of the compressive stress $\sigma_{\mathrm{c}}$ created in the overload plastic zone ahead of the crack tip is equal to the difference of the reduced stress $\left(\sigma_{\text {red }}\right)$ value and the maximum applied overload stress, that is, $\sigma_{c}=\sigma_{r e d}-\sigma_{\max , O L}$. The values of $\sigma_{\max , i}$ and $\sigma_{\min , i}$ are reduced by the value of the compressive stress $\left(\sigma_{c}\right)$ in each load cycle. The values of effective stresses $\left(\sigma_{\max }\right.$ eff,i and $\sigma_{\min }$ eff,$\left.i\right)$ in a fatigue cycle are respectively equal to:

$$
\sigma_{\max e f f, i}=\sigma_{\max , i}-\sigma_{c}=2 \cdot \sigma_{\max , i}-\sigma_{\text {red }} ; \sigma_{\min \text { eff }, i}=\sigma_{\min , i}-\sigma_{c}=\sigma_{\min , i}+\sigma_{\max , i}-\sigma_{\text {red }}
$$

The values must be positive numbers, otherwise it should be assumed that the value is zero.

The application of the above equations makes it possible to assess compressive stresses induced in the plastic zone ahead of the crack tip under an overload cycle in a particular block of stress. As an example, the overload plastic zone with the radius $r_{p, O L}=1.25 \mathrm{~mm}$ is associated with the crack of the length of $12 \mathrm{~mm}$ which propagates under the cycle with stress $\sigma_{\max , i}=186 \mathrm{MPa}$ and $\sigma_{\min , i}=-28 \mathrm{MPa}$ (block 1). The crack of the length of $a_{i}=12 \mathrm{~mm}$ penetrating the plastic zone is associated with the current plastic zone with the radius $r_{p i}=0.19 \mathrm{~mm}$. The stress that is required to be applied so that the crack could get through the overload plastic zone is $\sigma_{\text {red }}=72.8 \mathrm{MPa}$ and the compressive stress in the plastic zone is: $\sigma_{c}=-113.2 \mathrm{MPa}$. In accordance with equation (15) the effective stresses which induce the crack growth are $\sigma_{\text {max }}$ eff $, i=299.2 \mathrm{MPa}, \sigma_{\text {mineff }, i}=-85.2 \mathrm{MPa}$ $\left(\Delta \sigma_{\text {eff }}=214 \mathrm{MPa}\right)$. The crack length growth up to $13 \mathrm{~mm}$ within the area of the overload plastic zone but near its boundary $\left(a_{i}+r_{p O L}=13.25 \mathrm{~mm}\right)$ results in reducing the stress $\left(\sigma_{\text {red }}=59.2 \mathrm{MPa}\right)$ which is required for the crack to pass through the plastic zone. Simultaneously, the value of the compressive stress increases $\left(\sigma_{c} .=-126.8 \mathrm{MPa}\right)$. The above-mentioned values of the stresses, especially the compressive stress $\sigma_{c}$, contribute to delaying or even stopping the crack growth.

It should be stressed that hypothetical calculations concerning the plastic zone and the values of stresses in the Willenborg model refer to the cracks the length of which was determined for the geometry of fatigue tests specimen (Fig 1.) in accordance with the fracture mechanics principle. The values of compressive stresses assessed in accordance with the Willenborg model are consistent, in terms of values, with the values of stresses measured ahead of the crack tip with the use of the X-ray method.

Ultimately, the maximum and minimum values of the effective stress intensity factor are expressed by equations [21]:

$$
\begin{gathered}
K_{\max e f f, i}=K_{\max , i}-\left(K_{\max , o l} \cdot \sqrt{1-\frac{a_{i}-a_{O L}}{r_{p, o l}-r_{c p, U L}}}-K_{\max , i}\right) \\
K_{\min e f f, i}=K_{\min , i}-\left(K_{\min , o l} \cdot \sqrt{1-\frac{a_{i}-a_{O L}}{r_{p, o l}-r_{c p, U L}}}-K_{\min , i}\right)
\end{gathered}
$$

In order to check the correctness of the calculations concerning the predicted crack length and the crack growth rate carried out in accordance with the Willenborg model, the values of the crack length and the crack growth rate obtained that way were compared with the values determined experimentally for the LHL-100 block program loading. The results of the comparison are 
presented in the diagrams in Fig 8. Open symbols indicate values obtained by calculations, while filled-in-black symbols refer to experimentally determined crack rates.
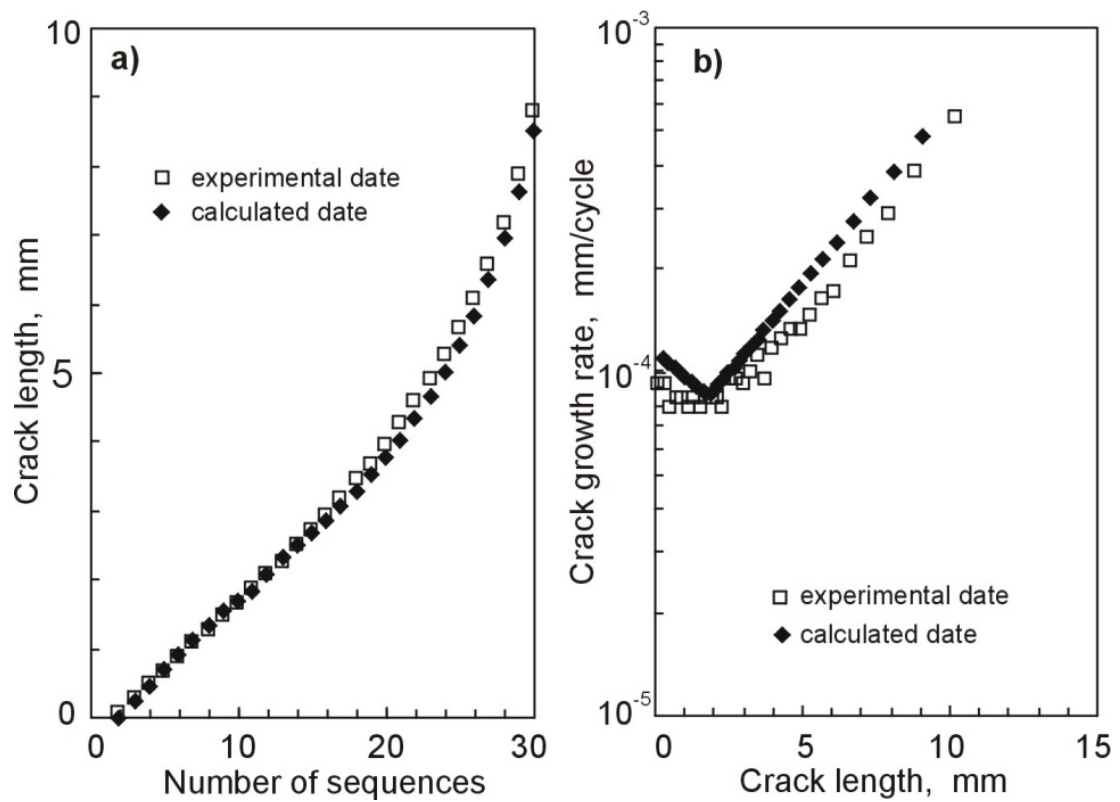

Fig 8. The comparison of the predicted crack length (a) and the crack growth rate (b) of specimens, the parameters of which were experimentally determined depending on the number of sequences and the length of cracks characteristic of the SRM-100 spectrum.

For the experimental fatigue crack growth and the crack growth rate curve $d a / d N=\mathrm{f}\left(\Delta K_{\text {eff }}\right)$, constants $m$ and $C$ were determined. For the decreasing part of the curve, the values of the constants are as follows: $m=-1.28$ and $C=5.11 \cdot 10^{-6}$. Whereas for the increasing part of the curve, $m=3.58$ and $C=3.2 \cdot 10^{-8}$.

Small differences in the arrangement of points in the zone of the growth of long cracks, especially in the diagram illustrating the crack growth rate depending on the crack length (Fig. 8 b), indicate the accurate assessment of the crack growth rate.

With respect to component safety, it is a favorable result since the component's predicted durability will be insignificantly lower than the experimental research shows. Therefore, the above diagrams prove that the calculation model presented above leads to the accurate values of the predicted crack length and the rate of the crack growth in components.

\section{SUMMARY}

The results of the experimental research concerning the fatigue crack growth rate both on the surface and inside the sheet of the 2024-T3 aluminum alloy under the LHL-100 block program loading with multiple overload-underload cycles was utilized to check the ability of the proposed deterministic approach for predicting the crack growth. In this approach the modified Willenborg retardation model was applied. The microfractographic analysis of fatigue fracture of the CCT sheet specimens with the use of TEM microscope made it possible to trace the effect of block program loading on the crack growth rate. For assessing the equivalent loading for the LHL block program the knowledge of the affectation of a particular overload-underload cycle or a block of these cycles on crack rate on the basis of microfractographic analysis was utilized. The crack growth rate inside the sheet was determined on the basis of fatigue striation spacing on the fracture surface of the CCT-type specimens. The microfractographic analysis proved that under the LHL100 loading program, the crack propagates approximately for the time that correspond to $4.2 \%$ of the spectrum operation. During a considerable time, the crack does not grow or it propagates at a 
very low rate. This behaviour of crack growth resulted from the affectation of plastic zones created by the block of cycles of highest stress level. The calculated crack growth rate was consistent with the experimentally determined crack growth rate.

\section{REFERENCES}

[1] Kocanda, S. (1978). Fatigue Failure of Metals. Sijthoff\&Noordhoff Int. Publishers.

[2] Kocańda, S. (1985). Zmęczeniowe pękanie metali [in Polish], $3^{\text {rd }}$ edition, Warszawa: WNT.

[3] Schijve, J. (2001). Fatigue of Structures and Materials. Kluwer Academic Publishers.

[4] Skorupa, M. (1996 June). Empirical Trends and Prediction Models for Fatigue Crack Growth Under Variable Amplitude Loading. Petten, Netherlands: Netherlands Energy Research Foundation. (ECN R-96-007)

[5] Skorupa, M. (1998). Load Interaction Effects During Fatigue Crack Growth Under Variable Amplitude Loading - a Literature Review. Part I: Empirical Trends. Fatigue and Fracture of Engineering Materials and Structures. 21(8), 987-1006.

[6] Kermanidis, A. T., \& Pantelakis, S. G. (2001). Fatigue Crack Growth Analysis of 2024-T3 Aluminium Specimens Under Aircraft Service Spectra. Fatigue and Fracture of Engineering Materials and Structures. 24(10), 699-710.

[7] Yisheng, W., \& Schijve, J. (1995). Fatigue Crack Closure Measurements on 2024-T3 Sheet Specimens. Fatigue and Fracture of Engineering Materials and Structures. 18(9). 917-921.

[8] Ellyin, F., \& Wu, J. (1999). An Numerical Investigation on the Effect of an Overload on Fatigue Crack Opening and Closure Behaviour. Fatigue and Fracture of Engineering Materials and Structures. 22(10), 835-848.

[9] Yasniy, P., \& Pyndus, Y. U. (2000). Prediction of fatigue crack growth rate after single overload at different stress ratios. In: Proceedings of the $14^{\text {th }}$ Biennial Conference on Fracture. Cracow, Poland, 8-13 September 2002. 3(3). 609-616.

[10] Schijve, J., Skorupa, M., Skorupa, A., Machniewicz, T., \& Gruszczyński, P. (2004). Fatigue crack growth in the aluminium alloy D16 under constant and variable amplitude loading. International Journal of Fatigue. 26(1), 1-15.

[11] Lazzeri, L., \& Ratti, G. (2002). Fatigue crack propagation in thin sheets under typical helicopter spectra. In Blom A. F. (Eds.) The $8^{\text {th }}$ International Fatigue Congress, 2-7 June 2002. 1(5). 585-592. Stockholm, Sweden.

[12] Iyyer, N. S., Kwon, Y. S., \& Phan, N. (2003). P-3C crack growth life predictions under spectrum loading. In: Proceedings of the $22^{\text {nd }}$ International Committee on Aeronautical Fatigue, 5-9 May 2003, ICAF: Fatigue of Aeronautical Structures as an Engineering Challenge, 2, pp.18. Lucerne, Switzerland.

[13] Skorupa, M. (1996). Empirical trends and prediction models for fatigue crack growth under variable amplitude loading. Petten, Netherlands: Energy Research Foundation. (ECN-R-96-007)

[14] Kocanda, D., Kocanda, S., \& Torzewski, J. (2004). Fatigue crack growth rate in an aircraft aluminium alloy under programmed loading and the capability of its reconstruction [in Polish]. Military University of Technology WAT Bulletin, 2(3), 69-83.

[15] Kocanda, D., Kocanda, S., \& Torzewski, J. (2004). Fatigue crack growth rate in the 2024T3 aluminium alloy under programmed loading and the capability of its reconstruction [in Polish]. In XXI Symposium on Experimental Mechanics of Solids, 2004, 23-44.

[16] Kocanda, D., Kocanda, S., \& Torzewski, J. (2004). Reconstruction of fatigue crack growth rate for the 2024-T3 aluminium alloy sheet on the basis of fractographic analysis. The Archive of Mechanical Engineering, 3, 361-375.

[17] Kocanda, D., Kocanda, S., \& Torzewski, J. (2005). Comparative study of fatigue crack growth rate in aircraft aluminium alloys under programmed loadings [in Polish]. In: 
Proceedings of the $3^{\text {rd }}$ Symposium on Damage Mechanics of Materials and Structures, July 2005, Bialystok University of Technology, 153-158.

[18] Kocanda, D., Kocanda, S., \& Torzewski, J. (2006). Variable amplitude load interaction in fatigue crack growth for the 2024-T3 aluminium alloy. In: Proceedings of the $16^{\text {th }}$ European Conference of Fracture, ECF-16, Greece 2006, 177-178 (abstract), full paper on CD.

[19] Kocanda, D., Kocanda, S., Torzewski, J., \& Werner, K. (2004). Plastic zones associated the fatigue cracking in aircraft aluminium alloy under programmed. Fatigue and Fracture Mechanics [in Polish]. In: Proceedings of the XX Symposium on Fatigue and Fracture Mechanics, University of Technology and Life Sciences, Bydgoszcz, 2004, 187-194.

[20] Kocanda, S., \& Szala, J. (1997). Foundations in fatigue calculations. PWN, Warszawa.

[21] Dowling, N. E. (1999). Mechanical behaviour of materials, $2^{\text {nd }}$ edition, Prentice Hall.

[22] Fuchs, H. O., \& Stephens, R. I. (1980). Metal fatigue in engineering. John Wiley \& Sons.

[23] Rama Chandra Murthy A., Palani, G. S., \& Nagesh, R. Iyer (2005). An improved Wheeler model for remaining life prediction of cracked plate panels under tensile-compressive overloading. SID, 1(3), 203-213.

[24] Bochenek, A. (1998). Elements of fracture mechanics. Częstochowa University of Technology.

[25] Torzewski, J. (2007). Fatigue crack growth rate in the 2024-T3 aluminum alloy under programmed loadings and the capability of its reconstruction on the basis of fractographic analysis. Ph.D. Thesis, Military University of Technology WAT. 